\title{
The Leadership of Transition: Correction, Conciliation and Change in South African Education
}

Jonathan Jansen ${ }^{1}$

Faculty of Education, University of Pretoria, Pretoria, 0002, South Africa

Email: jonathan.jansen@up.ac.za

\begin{abstract}
This paper focuses on educational leadership in the context of social transition to postapartheid democracy in South Africa. Transitional leaders manifest behaviours, attitudes, values and strategies that are deeply related to the contexts within which they work. Social norms and political climate may not be supportive of educational leaders wishing to rise to the challenge of unplanned transition; however this paper focuses on leaders who take up this challenge. Narratives of three educational leaders, two white and one black, provide an understanding of the complexities and challenges involved in bringing about change that goes against the grain of social, community, or institutional expectations. Five common strands that bind the narratives of the three leaders are revealed. These commonalities are: a sense of moral purpose, a sense of human frailty, a sense of racial inclusion, a sense of political complexity, and a sense of personal growth. In conclusion, seven propositions that may form the building blocks for new ways of thinking about leadership in post conflict societies are presented.
\end{abstract}

\section{Introduction}

In recent years I have tried to explore the character of leadership in transition societies (Jansen, 2005b). I was particularly interested in what leadership looks like when a society or a nation state moves from one kind of political and educational regime to another. In this focus on 'transition leadership' I sought to delve deeply into the social, emotional and political biographies of leaders and how their lives influenced, even directed, their commitments to leading for social justice (Jansen, 2005a). In 
researching these leadership stories I was always conscious of the dangers of drawing powerful, individualistic portraits of charismatic leadership acting against the odds; I was alert to popular images that favour heroic narratives of self-assured leaders who make neat-and-tidy decisions about injustice.

My research did indeed point to strong leaders, courageous decision-making, committed action, and deep conviction; but it also suggested messiness, uncertainty, imperfection, and struggle. It is this complexity of leadership, and its emotional and political correlates that constitutes the intellectual project behind this attempt to understand how leading for social justice unfolds in transition societies.

\section{Change and transition}

There is an established literature in political science about social transitions (O’Donnell, Schmitter, \& Whitehead, 1986) as well as studies about the relationship between education and social transitions in different states (Carnoy \& Samoff, 1990). In the organizational literature, there are studies of ‘transition leadership’ (Goldring, Crowson, Laird, \& Berk, 2003) but very few on the subject of educational leadership in contexts of social transitions.

A transition, for purposes of this article, is the movement from one kind of political regime to another kind of political order. Unlike the regular, orderly and predictable transitions that characterize democratic societies after planned election periods, I am focusing on transitions that are often dramatic, unexpected and infrequent in the history of a nation. Examples of such transitions would include the shift from colonial to postcolonial societies in much of the third world, the turn from authoritarian to democratic regimes in Eastern Europe, and of course the dramatic end of apartheid in South Africa and the advent of a post-apartheid democracy.

But such transitions are not simply changes of government; they also involve changes of institutions, of which education is arguably one of the most important sites through which to advance and contest new visions of a post-transition society. What makes the South African transition a particularly momentous context for the study of change is the long-entrenched system of colonialism and apartheid, and their effects on every aspect of the lives of black South Africa; the deep divisions and inequalities between white and black South Africans; and the challenges posed by the 
social, economic and educational legacies of apartheid for the process of transition. But there were two further peculiarities of the South African transition.

First, South Africa had a negotiated transition, one in which neither the white political order nor the black liberation movements 'won.' Unlike Mozambique or Angola, for example, in which there was a decisive victory for the liberation forces who could create a new society on a clean slate, South Africa was forced into a protracted series of negotiations in which erstwhile enemies would together define the new ordereven though it was understood that the black political movements would gradually and decisively take the lead following national democratic elections in which the electorate was so overwhelmingly black.

Second, South Africa had a strong and settled white community so that unlike Namibia, Zimbabwe or Kenya, the ambition and extent of social change, including educational change, would be strongly conditioned by the fixed presence of a large and established white minority constituency. In addition to specific protection clauses that were formally negotiated between the white Nationalist Party and the former liberation movements, there were broader political understandings that any dramatic shift of resources from white to black hands, for example, would not only undermine economic confidence in the country, it would also lose the participation of white South Africans in the social and political life of the new nation.

It is within this context that I explore the following questions:

- What kinds of leadership emerge in educational institutions in the context of negotiated transitions?

- What is the character of leadership that seeks to reconcile differences and transform education in such transitions?

- What are the emotional lives of leaders leading for social justice in transition societies?

- How do leaders, black or white, lead in ways that recognize injustice and inequality, on the one hand, and seek reconciliation and justice on the other hand?

- Why do leaders for social justice take on this task, often at considerable personal cost?

- How do transition leaders understand the process of transition itself? 
- What are the kinds of struggles and challenges faced by those who lead for social justice?

- What are the (non-material) resources that leaders for social justice draw on?

- How do transition leaders deal with setbacks and disappointments in their striving for social justice?

- How do leaders balance the interests of contending groups as they simultaneously seek redress and reconciliation?

- What is it about these leaders' biographies that explain their commitments?

- How do these leaders deal with their own biographies of experience when they face challenge and resistance from within or outside their 'own' groups?

These questions form part of a larger research program and not all are equally addressed in this particular article; however, these questions about transition leaders are crucial to understanding the quest for change in complex societies in which there is a shift from one political regime to another.

\section{Race, leadership and transition in South Africa}

The research reported here draws on two separate strands or accounts of leading for social justice in transitional South Africa in the period 1994-2004. It is an account of those leaders who lead against the grain of public expectation and against the logic of their own biographies. It would indeed be a relatively simple matter for change theory if leaders behaved predictably; if leaders' commitment to change could be read off against their race, class and gender identities. But this is not always the case. The first account concerns two white, Afrikaner principals who decided to radically change their schools into racially and culturally inclusive institutions in the face of tremendous pressure from the traditional communities served by these schools. My ongoing interviews with these principals attempt to dig deep into personal biography including family background, educational experiences, racial ties, community expectations, and shaping influences. I was particularly interested in critical incidents i.e. moments of personal challenge or transformation in the lives of these principals that could explain their commitment to changing the racial complexion and culture of their schools at the levels of student enrolments, staffing and curriculum. I wanted to 
know why they did not take the easy route of what we call 'the counterpoint schools'-those lily-white schools across the road from their own schools whose governing bodies control admissions and appointments in ways that ensure racially exclusive and culturally homogenous institutions.

The second account is a personal narrative about my own role as a black Dean in a former white, Afrikaner university in the period 2001-2005. I had decided to take on this position to lead the transformation of the large Faculty of Education and to participate in the broader change process at the University of Pretoria. I documented through regular diary entries my experiences of the change process. I focused sharply on the emotional and political challenges I encountered as I sought to create a more inclusive and more just environment in which students, staff and the broader community of parents, alumni and school principals could feel part of, and benefit from, the process of change. In this account I also draw attention to critical incidents in my life as black Dean in a white university, and what these events reveal about personal struggles, institutional culture, and the nature of change under conditions of transition.

In other words, these two accounts of two sets of leaders leading against the grain are brought into conversation to reflect on race, leadership, and social justice in the context of South Africa's dramatic though negotiated transition from apartheid to a democratic state. The grounds for comparison in the same country are perhaps obvious: white principals, as racial insiders, compelled by their own biographies to transform white schools of which they were always a part; and a black Dean as racial outsider, propelled by the logic of his own biography, to transform a white university from which he was, until recently, excluded.

\section{Leadership and change as racial insiders}

Sarie Marais and Jan De Wet are principals of former white, conservative, urban schools in two major cities in South Africa, Johannesburg and Pretoria, respectively. These two co-ed high schools were until 1994 all-white institutions with a single language of instruction, Afrikaans. The schools were both named after prominent Afrikaner politicians (a President and a Prime Minister) whose ascent to power came during the highpoint of Afrikaner nationalism achieved under apartheid rule. These schools were therefore proud beacons of Afrikaner nationalism and home to 
generations of Afrikaner children whose social, cultural and political identities were intimately tied-up with the institution. The powerful complex of religion (Afrikaner Calvinism), language (Afrikaans), sport (mainly rugby and netball) and culture (festivals and competitions representing Afrikaans literature, poetry and music) unmistakably defined the institutional cultures of these schools. Walking down the hallways of these schools are impressive symbols of Afrikaner power and privilegefrom the larger-than-life busts of the patriarchs after which the schools were named, to the long series of black-and-white photos adorning the walls of each institution and showing proud, all-white faces of sporting, academic and cultural heroes of each institution; to the trophies of sport achievements brightly adorning the cabinet displays. To enter these schools is to be impressed by the scale of organization, the impeccably uniformed students, the polite and warm reception of visitors (Goeie More!), the ordered and efficient shuffling of students between classes, the predictable timetables, the absolute quiet around the school once classes are in session, the purposeful walk of every teacher, and the esteem with which the principal is held within the school. It is a community in which education is highly valued, and in which the school leader is highly regarded. It makes perfect sense to me why such a large majority of pre-service teachers emerge from these kinds of schools and from these kinds of communities. It also raises the question as to what would happen to a school leader who steps out of this white, ordered, tightly-knit and insular environment to challenge and change this unanimity of race, culture and community.

\section{Leadership and change as racial outsider}

Jefferson Hansen is the first black Dean of the Faculty of Education at the University of Pretoria. Situated in the shadows of the Union Buildings, the seat of nationalist governments, this University remains one of the largest residential institutions in South Africa. Appropriated by Afrikaner nationalism, the University of Pretoria was an all-white institution that reproduced the ruling classes of the apartheid era in every sphere of national life. With Afrikaans as the language of instruction, administration and governance, the University of Pretoria played a crucial role in sustaining the cultural, social and religious underfelt on which the harsh politics of white domination would play itself out. The University takes its name from the white Boer leader who claimed to found Pretoria, Andries Pretorius; on the emblem of the institution stands, 
to this day, an oxwagon symbolizing the 'voortrekkers' who trekked North from the liberal Cape province to establish the two Boer republics of the Orange Free State and the Transvaal. The University reflects all the benefits of a privileged racial past with its impressive laboratories, its multicampus infrastructure stretching from its famed business school in the lush Sandton area of Johannesburg to its main campus in Pretoria to its prominent Veterinary Faculty further North in Onderstepoort and its world-class High Performance Centre to which athletes from all over the world flock for state-of-the-art training. The buildings are well-maintained, the lawns perfectly groomed, the gates guarded by well-groomed security personnel. Almost every building announces itself in both English and Afrikaans, reflecting political compromises of long ago among the two major white groupings-Boer and Brit- to establish two national languages under the racial state. Yet, to the trained eye, the Afrikaans always appears first, where the name boards are written horizontally, or on top, where the words are written vertically. In this simplest of symbolisms, Afrikaans unmistakably dominates. It was into this environment that Jefferson Hansen would step as a black Dean with a commitment to creating a more inclusive student body, faculty, curriculum and ethos starting in the Faculty of Education.

\section{The personal and political terrain of leading for social justice}

Comparing the experiences of the two sets of leaders, a number of common strands bind their narratives in very powerful ways.

\section{A sense of moral purpose}

The first point to make about these leaders is that they hold a strong sense of social justice, and of the imperative to open up opportunity in these well-resourced, recently all-white institutions to all South Africans. They do what they do not on the basis of some superficial attempt to boost student enrolments, and therefore retain government subsidies; or to elevate black staff numbers and therefore meet legal requirements for 'employment equity.' On the part of these three leaders, there are deep commitments to change, to correction and to community.

In the case of the white principals, this strong sense of purpose runs counter to their own upbringing and socialization. They were formed in the heart of white conservatism and gained their social consciousness during the resurgence of Afrikaner 
nationalism. They attended all-white churches, all-white schools, all-white universities, and all-white social settings. They observed parents in charge of, or responsible for, black workers. They learnt all the myths of white superiority and black inferiority. And yet these white principals turned against that powerful socialization to transform their schools into inclusive communities.

They were racial insiders, and this came at great cost. Both principals tell of marginalization in the white community; the difficulty of watching some parents withdraw their children and placing them in all-white schools across the road; the calculated comments about 'selling out' Afrikaners to the black nationalist government; the pain of observing the shrinkage of the social circles of their own children. At the same time, the principals talk of new friendships, broadened horizons, and a determination that speaks of not 'going back' to a former, white world of privilege and insularity.

In the case of the black Dean, his upbringing in a conservative, black evangelical church did not shield him from the harsh violence of apartheid which gradually shifted him towards the politics of black consciousness. He recalls incidents since early childhood of racial slander and abuse; he remembers experiences of segregation with black passengers crowded into the back of the railway bus and a single white passenger in the well-ventilated front of the bus; he records stories of torture and killings in the streets where he lived and in schools were he taught of young men and women by the 'riot police' in his township; he tells of the hardships going to a faraway black university specifically designed for what was thought to be his ethnic group, miles from the white university close to home; and he remembers the gradual radicalization of his social views.

He was a racial and cultural outsider to the University of Pretoria. Black comrades viewed his role with some suspicion; white colleagues now say openly that they did not believe he would survive, let alone thrive, within the institution. Yet he enjoyed strong support from the university principal, and found, with few exceptions, willing followers and support among his colleagues. To be sure, there were moments of great frustration with the hierarchical, authoritarian, inflexible and in many ways racially exclusive patterns of social interaction amongst most of his senior white colleagues. At the same time, he worked with alternative networks of black and white colleagues who understood the broader goals of transformation and shared the same values. He wanted to be in this place. 
Both sets of leaders, despite the complexity and challenges of the task of building social justice and inclusiveness, remained strong in their commitment to institutional change and transformation. Despite recording feelings of marginalization and exclusion, they also tell of experiences of inclusion and acceptance. Their networks broadened, their circles of colleagues and friends enriched, and their resolve to continue leading remained firm.

\section{A sense of human frailty}

I found that both sets of leaders were keenly aware of their own limitations, their personal prejudices, and their troubled histories as South Africans. They do not pretend that the past did not happen, or that their personal lenses are untainted by years of growing up as either part of a privileged and dominant racial minority in an African country - in the case of the principals — or as part of an oppressed majority under white rule, in the case of the dean.

Each of the principals recorded 'critical incidents' that challenged their commitments to the core. The woman principal recalls with the traumatic incident of black male students refusing to leave her office after being summonsed for a disciplinary inquiry, and how she had to call senior colleagues to assist in moving the students. This had never happened before in the former white school. In a cultural environment where the authority of the head was firm, visible and unchallenged, this confrontation was serious and unprecedented; it also threatened to be read as a racial confrontation, and this could unravel hard-won gains made in recent years.

What was interesting about the response of the principal was, first, the deeply emotional impact of this first serious challenge to her authority by black students; and second, her ability to locate the problem as lying outside of the students. She brought into the school senior black colleagues from the district office, and sought ways in which to restructure the school's management strategies and the school's disciplinary problems in order to better anticipate and prevent such incidences from recurring. She was conscious of the fact that the lack of senior black deputies limited her capacity to deal with such problems credibly and effectively.

In telling these and other stories, the principals constantly reflect on their own imperfections, their sense of personal struggle, and their initial attempts to seek appointment in the security of all-white schools. The firmness of resolve coexists with awareness of frailty. The strong hand of management works in tandem with the soft heart of leadership. Strategic decision-making recognizes emotional vulnerability. 
The black Dean also finds himself having to work through the biography of his own experiences. He finds himself agitated by the initial lack of responsiveness of conservative white males; by the physical distancing of white women during meetings; by what appeared to be confrontational approaches of white students; by the tendency towards issuing commands by some white colleagues and seniors; by the overwhelming whiteness of key decision-making bodies in the institution.

One powerful incident was a visit by a senior administrator who instructed the Dean, in the didactic tones of an authoritarian teacher, what was required in writing an annual entry into the university yearbook. Hansen responded by asking the administrator to leave his office and to come back when he knew how to speak in a collegial and constructive manner. The senior administrator did come back, changed his tone, and they became good friends. Another incident involved a white dean who insisted on addressing Hansen, whom he hardly knew, as “my friend” while addressing all other senior people as 'professor X.' Out of context, this might sound like a fairly innocent, even affectionate treatment of a colleague. In the South African context, used by whites on blacks, it more often conveys an attitude of racial paternalism. Again Hansen corrected his colleague, in public, and that was the end of such behaviour.

What was significant in these exchanges was the difficulty of navigating the daily routines of a white institutional culture, its emotional toll on black leadership, and the challenge to survival on the part of racial outsiders. Hansen is aware of the possibility that he could be 'overreacting', a term often used to dismiss black anger; he is also conscious of the fact that sometimes innocent events could be interpreted through the lens of a deeply racialized experience in ways that might not be accurate or fair to the intentions of a colleague or administrator or student. Hansen knows that as much as he has to challenge and confront authoritarian and racist behaviour, he simultaneously has to 'work through' the complex emotions—-hurt, pride, anger, caution-that form him. He, too, is conscious of human frailty even as he asserts and leads for social justice.

\section{A sense of racial inclusion}

These leaders project a broad and generous sense of social justice which is, at its core, inclusive in policy and practice. This is a complex balancing act for two reasons. First, to bring-in non-traditional students or staff is to immediately threaten those who regard institutions as 'their own' and therefore incomers as outsiders; the challenge in 
such a case is to both retain the interests and commitment of the traditional clients of the institution even as a more inclusive environment is being built. Second, to bring-in newcomers are not simply a physical act of spatial accommodation; it is also a political act of social, cultural, emotional and linguistic inclusion.

The two principals resist the all-too-common standpoint of white schools that black students coming in do so on the terms of the school. That is, that black children acknowledge and accept the cultural, linguistic and social arrangements that dominates in their new school. These leaders understand the importance of inclusion and accommodation, and of the need to create a broader and more diverse school climate.

The emphasis with which this principle is pursued varies for the two principals. Sarie Marais is ambitious in this regard. She changes the name of the school from Hoerskool JG Strijdom (a prominent Afrikaner nationalist prime minister) to Diversity High; there could be no clearer signal of what this school intended. She introduces anti-racist workshops led by black staff from a non-governmental organization called the Centre for the Study of Violence and Reconciliation. She hires black teachers and heads of department - the Achilles heel of white South African schools whom, when pressured, are more comfortable to limit inclusion to black students. She brings in advisors who are prominent black educators and administrators to advise her on the transformation of the school.

Jan de Wet is more cautious and a little reluctant to accommodate what he calls "anti" discourses in the school. He wishes to introduce newcomers to the traditions of the school as well as exposing the insiders to broader South African culture. He actively creates leadership opportunities within his school for black and white students. He strongly seeks to build an integrationist culture within the school community with a keen eye on opening access for students to all languages and traditions.

Dean Hansen shares the same perspectives as his principal colleagues in seeking to build on those insider traditions that enable inclusion and accommodation while introducing new traditions that reflect the broader community of staff and students. For Hansen, integration, inclusion and recognition are core values in his leadership. A key event in this regard is the weekly lunches with ten first-year students served by the Dean. Hansen specifies that five white and five black students should attend, or else the students would come by race. The lunch is an opportunity to meet the Dean and to discuss anything of interest to the students except academic work. The 
language used in these sessions flows freely between English (accommodating the black students, though in their second or third language) and Afrikaans (accommodating the white Afrikaans students, though they understand English). The weekly lunches, now an institution, serve several less obvious objectives. First, to enable students to understand that in a hierarchical organization with durable topdown traditions, access to leadership is possible and valued. Second, to provide an opportunity — often for the first time - for white and black students to come together in a social or non-academic context. Third, to communicate through the languages used (English and Afrikaans) and the form of assembly (an informal lunch) that integration and accommodation are highly valued in this academic community. And fourth, to create a platform for ongoing dialogue with students that would not be easy if their only contact with Hansen was through formal addresses, class lectures or the presentation of student complaints.

For Hansen, the long-term transformation of the Faculty and the University depends on several things happening simultaneously: diversifying the student body as well as the academic staff; changing the curriculum to include a broader range of scholarly traditions, and especially the more critical traditions; altering the symbols and architecture to signal greater inclusiveness; and leveling the processes of decisionmaking to be more democratic and inclusive, and in ways that enable logic, rationality and dialogue rather than seniority, rigidity and die opdrag to dictate how people respond to authority and to each other.

All three leaders therefore work against a displacement logic in which one group of people or one set of cultural traditions moves in to supplant or displace what existed for decades in these white institutions. They want both: the new and the old; tradition and diversity; continuity and change; white and black. But they want it in ways that enable deeper institutional transformation rather than a simple additive function between the two (or more) communities and their cultures.

In seeking to build such socially inclusive cultures, their styles and emphases vary and the degree to which these core values are achieved in practice differ across the three campuses.

\section{A sense of political complexity}

The two sets of leaders are keenly aware of the difficult terrain on which they pursue social justice and racial inclusion. The political transition was an elite transition; for ordinary South Africans, there was no manual or playbook to guide the process of 
reconciliation and reconstruction. The political transition was threatened early on by right wing extremists; the constitutional negotiations were highly sensitive and contained built-in protection clauses against radical change; the new state was highly sensitive to the international repercussions for the economy if political action was deemed as targeting white social and economic interests. In the educational sphere there was great caution with respect to maintaining a strong public school sector rather than instigating white flight to private or independent schooling. This was difficult terrain in which to lead a school or change a Faculty in which white interests were so strongly represented and white values so deeply entrenched.

The two principals are conscious of the fact that they stand between two racial poles: the now black-led department of education representing the new government and the white parent community representing the interests of Afrikaners. The former seeks 'transformation' of these former bastions of white privilege; the latter seeks retention of the cultural and language (Afrikaans) rights of the white community. To keep both, the support of the departmental bureaucracy and white parents is an act of great complexity.

For white parents, the assertion of their rights and expectations come cast in the ubiquitous if troublesome language of 'standards,' and in South Africa the clearest signal that 'standards are being maintained' is the Grade 12 or matriculation examination results. Both principals are aware of this, and are keen to point out that despite the desegregation of their schools, they have been able to maintain close to $100 \%$ pass rates in this end-of-school examination with a significant number of matriculation exemptions i.e. university-level passes. Both leaders express some agitation that despite proving that integration did not impact negatively on aggregate performance, some white parents still took their children out of their schools. They realize, of course, that the standards argument is for some parents a code word for anti-integration and not a serious concern about scholastic standing. Yet they dare not allow academic performance to be the legitimate grounds for the withdrawal of white students.

For Hansen, the political complexity is much more direct. His undergraduate class consists of more than $90 \%$ white, Afrikaner students and very few black students. The reasons are simple: black schools, especially since 1976, have been largely dysfunctional after years of protest action against apartheid centered on the schooling system. While white schools were largely untouched by the student uprising, the 
tremendous courage of black youth in anti-apartheid resistance left in its wake township schools with a very weak culture of teaching and learning. As a consequence, the teaching profession had developed a very negative image amongst black youth with very few choosing to become teachers.

For Hansen, this stark reality meant that any dramatic changes in the teaching staffwhich had to remain largely Afrikaans-speaking and therefore, largely white-would immediately mean losing these undergraduates to rival white Afrikaans colleges, leaving his Faculty with a serious enrolment crisis. The opportunities, therefore, for bringing greater balance and diversity into the academic teaching staff were seriously constrained by the politics of numbers. Similarly, the reform of curriculum could not represent too huge a leap into radicalism—even though some of the new academic recruits were eager to move in this direction with respect to radical pedagogies and new race theories. In time, the reform of a largely conservative teacher education curriculum was inevitable-but the pace and packaging of changes in instructional content would always be subject to this hard political calculus, at least until such time that more visible numbers of black undergraduates could be recruited. This steady but slow transformation of academic appointments was not easy in the context of persistent governmental pressure for what South Africans call 'employment equity.' This simple case also draws attention, again, to the ways in which laudable policy goals struggle to find expression in practical contexts governed as they are by a range of political and strategic considerations, which leaders have to take into account.

\section{A sense of personal growth}

None of the three leaders took up their positions fully prepared and trained for the task. In this respect, the literature on educational leadership often presents fully formed leaders acting out their wisdom with great energy along a straight line of reform. They change schools; little is known about how they change themselves. What the stories of the South African educational leaders demonstrate is that these leaders themselves change, and that they change gradually, as they proceed to transform their schools for greater inclusion and affirmation. There was no Damascusroad experience or dramatic turning point in the lives of these white school leaders. The principals started off with an initial commitment to change, but gradually found their own perceptions, emotions, and actions being transformed through positive engagement with black students, black parents and black district officials. 
These leaders challenge the notion of the great, charismatic leader with a powerful vision that leads willing followers all by him-/herself to change schools with unwavering conviction to conform to the expectations of their communities. Quite the opposite.

Sarie Marais' initial impulse was to flee to the racial security and familiarity of an allwhite school. In fact, she enrolled her son in the counterpoint school and is conscious of the contradictions in this decision. Jan de Wet is conscious of the limitations of what his school has achieved with respect to black teachers and black governors. Jefferson Hansen recognizes that changes to curriculum are constrained by the capacity and biographies of the racial insiders on his academic staff. To change too radically away from the competence and experience of your teachers, is to court disaster in the classroom.

The principals talk with remarkable candour of how they changed in the course of opening their schools for greater inclusion. They tell of new insights into managing diversity; they speak openly of how their racial preconceptions of black behaviour were challenged by what they observed in practice.

Sarie was reluctant to include soccer on the school program because of her association — and that of many whites — of this sport with violence. Yet when she witnessed the young boys engaging in the sport on her school grounds, she saw only joy and exuberance among black youth as they played the great game. She was equally reticent about hiring the school facilities for a black funeral, not sure in her mind whether the school would be overcrowded and unmanageable when the mourners arrived. Yet what she saw was the highly dignified and somber mourning of people from the black community associated with the school. What is striking about these two incidents is not the observation itself, but the readiness of Sarie to share these stories of personal growth and development as a white principal.

Dean Hansen recalls the influence of black consciousness in his own life and the very firm views of whiteness and white behaviour; for him, the world was primarily a division not of class but race. Yet as he encounters white students from poor and rural backgrounds, he recognizes the common struggles of parents despite the privileges bestowed by apartheid on Afrikaners. His personal growth came through a powerful understanding of the intersection of race and class in the lives of working class and poor white students. This translates into a strategy for raising scholarship support for both black and white students; and one in which staff development through research 
training and support were shared equally with white and black faculty. For Hansen, questions started to arise in his own consciousness about the devastating effects on white students and white faculty of the apartheid system. While understanding the imperative of affirming black students and black faculty within this former all-white institution, it was done in a way that included white colleagues and students. This kind of growth in understanding was light years away from Hansen’s political socialization prior to coming to Pretoria.

\section{Towards a theory of transition leadership in post- conflict societies}

The theoretical implications of this study of transitional leaders are crucial in studies of social justice and educational change. It is clear from these studies that transitional leaders manifest behaviours, attitudes, values and strategies that are deeply related to the context within which they work. Generic statements about leaders and leadership clearly have limited significance in settings where, for example, racial reconciliation and social justice are demanded in the broader political context. In such cases, transition leaders find themselves pursuing both imperatives_-bringing together deeply divided groups of people while at the same time ensuring that access and opportunity are expanded beyond the traditional communities served by institutions. But leaders are as likely to resist as to embrace change and transformation. It is not at all the case that leaders automatically rise to the challenges of transition in their contexts. This is especially the case in settings where leaders (e.g. white South African schools) are more likely to understand inclusiveness and correction as acting against their own entrenched racial interests; or where black leaders in white universities, for example, act partially in the interests of one group of people only. Hence the focus of this research on leaders who embrace change against the grain of social, community or institutional expectations.

In conclusion, what is now needed is a theory of transition leadership in which the following propositions, drawn from the three case studies, could form the building blocks for new ways of thinking about leadership in post-conflict societies: 
1. that context shapes the kind of leadership possible or even desirable within educational systems; generic or normative statements about leaders must be contextualized.

2. that complexity underpins leadership behaviours in transitional contexts; idealistic stories of personal heroism simply do not hold.

3. that courage in leadership sets the limits and possibilities for what can be achieved in deeply divided societies; 'soft concepts' such as courage (and allied concepts such as hope and spirituality)are under-theorized in the managerial emphasis in the leadership of change literatures.

4. that contradiction in leadership behaviours explains progression and regression in educational change; unproblematic upward progress in the trajectory of change does not reflect grounded experiences of leaders in challenging contexts.

5. that culture and not only materiality lies at the heart of complex change in divided societies; who holds ownership over the cultural goods of a school (language, religion, sport, symbolism etc), who gains access to these goods, and the degree to which such cultural goods are open to negotiation (sharing, removing, adding...) has yet to be theorized within transition states.

6. that credibility (not only capability) is crucial in winning over divided constituencies behind a unifying project in post-conflict societies; it is the act of being seen to be fair and even-handed, and of living public lives that demonstrate the ideals of compassion and community, that present more than a declared moral or political standpoints on what is required.

7. that conciliation must inform a theory of leadership in divided societies; that is, how does one explain that complex capacity of transition leaders to bring together divided communities in ways that both assert correction (righting the wrongs of the past) and demonstrate compassion on both sides of the divide, and in ways that keep everyone on board? 


\section{References}

Carnoy, M., \& Samoff, J. (1990). Education and social transition in the third world. Princeton, NJ: Princeton University Press.

Goldring, E., Crowson, R., Laird, D., \& Berk, R. (2003). Transition in a shifting policy environment. Educational Evaluation and Policy Analysis, 25, 473-488.

Jansen, J. (2005a). Black dean: Race, restitution and the emotions of the deanship. Harvard Educational Review, 75(3), 306-325.

Jansen, J. (2005b). The color of leadership. The Educational Forum, 69(2), 203-211. O’Donnell, G., Schmitter, P., \& Whitehead, L. (1986). Transitions from authoritarian rule: Tentative conclusions about uncertain democracies. Baltimore, Maryland: John Hopkins University Press. 